\title{
Apolipoprotein A-I and Its Amphipathic Helix Peptide Analogues Inhibit Human Immunodeficiency Virus-induced Syncytium Formation
}

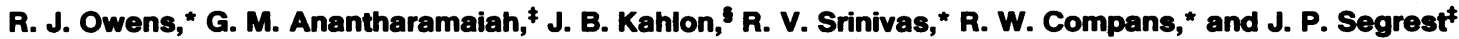 \\ Departments of ${ }^{*}$ Microbiology, ${ }^{\ddagger}$ Medicine and Biochemistry, and Atherosclerosis Research Unit, University of Alabama in Birmingham \\ Medical Center, Birmingham, Alabama 35294; and ${ }^{\S}$ Southern Research Institute, Birmingham, Alabama 35255-5305
}

\begin{abstract}
The envelope (membrane) glycoprotein of HIV is essential for virus attachment and entry into host cells. Additionally, when expressed on the plasma membrane of infected cells, the envelope protein is responsible for mediating cell-cell fusion which leads to the formation of multinucleated giant cells, one of the major cytopathic effects of HIV infections. The envelope glycoproteins of HIV contain regions that can fold into amphipathic $\alpha$-helixes, and these regions have been suggested to play a role in subunit associations and in virus-induced cell fusion and cytopathic effects of HIV. We therefore tested the possibility that amphipathic helix-containing peptides and proteins may interfere with the HIV amphipathic peptides and inhibit those steps of HIV infection involving membrane fusion. Apolipoprotein A-I, the major protein component of high density lipoprotein, and its amphipathic peptide analogue were found to inhibit cell fusion, both in HIV-1-infected T cells and in recombinant vaccinia-virus-infected CD4+ HeLa cells expressing HIV envelope protein on their surfaces. The amphipathic peptides inhibited the infectivity of HIV-1. The inhibitory effects were manifest when the virus, but not cells, was pretreated with the peptides. Also, a reduction in HIV-induced cell killing was observed when virus-infected cell cultures were maintained in presence of amphipathic peptides. These results have potential implications for HIV biology and therapy. ( $J$. Clin. Invest. 1990. 86:1142-1150.) Key words: HIV • apolipoprotein $\bullet$ HDL • amphipathic helix • antiviral activity
\end{abstract}

\section{Introduction}

The human immunodeficiency virus is widely accepted as being the etiologic agent responsible for AIDS. The HIV envelope (membrane) glycoprotein is synthesized first as a polyprotein, gp160; it then is cleaved intracellularly to give rise to a gp120-gp41 complex and transported to the plasma membrane (1-4). This cleavage event has been shown to be necessary for viral infectivity and for the formation of multinucleated syncytia by cell-cell fusion, the major cytopathic effect of HIV infections (5). After cleavage, a new hydrophobic amino terminus is exposed on gp41 that is important for mediating fusion of the viral envelope with a cellular membrane, leading

Address reprint requests to Dr. Jere P. Segrest, Department of Medicine, $630 \mathrm{BDB}$, University of Alabama in Birmingham, Birmingham, AL 35294.

Received for publication 18 May 1990 and in revised form 5 June 1990.

J. Clin. Invest.

(c) The American Society for Clinical Investigation, Inc. $0021-9738 / 90 / 10 / 1142 / 09 \$ 2.00$

Volume 86, October 1990, $1142-1150$ to release of the viral nucleocapsid into the cytosol $(6,7)$. The process of virus-induced cell fusion is thought to be analogous to the process involved in fusion of viral membranes with cell membranes and interruption of this process has been shown to reduce viral replication and syncytium formation in a number of virus systems (8-13). In model membrane systems, certain agents that stabilize the membrane bilayer have been shown to inhibit membrane fusion $(14,15)$.

Amphipathic $\alpha$-helixes were initially described in the structures of myoglobin and hemoglobin (16), and contain opposing polar and nonpolar faces, which are readily visualized in "helical wheel" diagrams showing the asymmetric distribution of nonpolar and polar residues along the axis of the helix (17). The amphipathic helical structures have been identified in a variety of proteins, particularly apolipoproteins, and may account for their strong affinity for phospholipids (18). This hypothesis has been supported by structure-function studies with synthetic peptide analogs (19-25). Examples of other amphipathic helix-containing proteins include certain lipid-associating polypeptide hormones (for example, $\beta$-endorphin and calcitonin) (26), novel antimicrobial agents, such as magainins (27), cecropins (28), as well as type I and type II (IFN- $\gamma$ ) interferons (29). Recently, several reports have indicated the presence of potential amphipathic helical domains in the HIV envelope glycoprotein. Two potentially amphipathic helical domains that display a high mean hydrophobic moment within the carboxy terminus of gp160 have been predicted by computer modeling; one is located 70 residues from the carboxy terminus between amino acids 768-788 and the other directly at the carboxy terminus between amino acids 826-854 (30). There are additional regions in gp1 20 and gp41 that can form amphipathic helical domains, some of which are conserved in different isolates of HIV-1, HIV-2, and Simian immunodeficiency virus, and these regions are thought to be involved in gp120-gp41 subunit interactions (31). Studies on the topology of HIV-1 gp160 in membranes have shown that the carboxy terminus is inaccessible to proteases or sequence specific antibodies, and indicate that the carboxy terminus of gp41 may be associated with the membrane bilayer (32). The peptide analogues of these helixes have been suggested to mediate fusion of lipid vesicles (30). Although mutational analyses of the carboxy-terminal region of the gp41 subunit include conflicting data from different laboratories, they nevertheless suggest that the carboxy terminus of gp41 may be required for viral cytopathology $(33,34)$. Like apo A-I amphipathic peptides, the gp4l carboxy-terminal amphipathic peptides also contain positively charged residues at the polar-nonpolar interface, although the polar faces of gp41 amphipathic peptides are significantly more basic. In contrast to apo A-I amphipathic peptides, synthetic peptides corresponding to gp41 amphipathic peptides were found to be lytic, and toxic to cells (unpublished observations). 
Because of the marked bilayer affinity of amphipathic helical peptides of the apolipoprotein type, their similarity to gp4 1 carboxy-terminal amphipathic peptides and lack of cytotoxicity, we investigated the possibility that these structures might inhibit HIV-induced membrane fusion. A number of amphipathic peptide analogues of apo A-I with a wide spectrum of affinities for phospholipid bilayers have been synthesized and characterized $(19,23)$. Four peptide mimics of apo A-I, the major protein of HDL, with amphipathic helical structures and differing lipid affinities were studied for their effects on cell fusion. We have also investigated the effects of these peptides upon HIV infectivity and the viability of HIVinfected cells.

\section{Methods}

HDL, apo A-I, and synthetic amphipathic peptide analogues. HDL and apo A-I were prepared according to previously described procedures and purified by HPLC (35). The peptides were synthesized by a solidphase method in which benzyl-based protecting groups were used for side chain protection, and released from the resins as described earlier (19). The peptide synthesis was carried out using an automated peptide synthesizer (Advanced Chemtech, Inc., Louisville, KY). All the peptides were purified by HPLC, and purity was verified by thin-layer chromatographic analysis, amino acid analysis, and sequencing. The peptides used include: (a) 18A, an 18-residue-long peptide capable of forming an amphipathic helix, which contains positively charged arginine residues at the polar-nonpolar interface; $(b) 37 \mathrm{aA}$, a dimer of $18 \mathrm{~A}$ linked via an alanine residue (18A-ala-18A); (c) 37pA, a dimer of $18 \mathrm{~A}$ connected via a proline residue (18A-pro-18A); $(d) 18 \mathrm{R}$, in which positions of the charged residues are exchanged so that resulting helix contains negative charges at the polar-nonpolar interface of the helix; and $(e) 18 \mathrm{~S}$, in which the residues in $18 \mathrm{~A}$ were scrambled so that they did not form any amphipathic helix. The primary sequence and helical wheel representation of these peptides is shown in Fig. 1.

Cells and viruses. Vero cells (clone 76; American Type Culture Collection, Rockville, MD), and CD4+ HeLa cells (6) were maintained in DMEM supplemented with $5 \%$ newborn calf serum. Uninfected Sup T1 cells, MT-2 cells (36), and H9 cells persistently infected with $\mathrm{HIV}-\mathrm{III}_{B}$ were maintained in RPMI supplemented with glutamine and $10 \%$ fetal calf serum. The HTLV-III ${ }_{B}$ strain of HIV-1 was obtained from Dr. Beatrice Hahn (University of Alabama at Birmingham [UAB]), and maintained by serial passage in H9 or MT-2 cells. Poliovirus type 1 (Mahoney) was obtained from Dr. Casey Morrow (UAB), and maintained by serial passage in HeLa cells. A recombinant vaccinia virus (VV), ${ }^{1}$ VVenv1, which expresses the HIV-1 envelope protein, was described previously (37). A recombinant vaccinia virus (rVV) expressing the HIV-2 (ROD), envelope protein, VVHIV2(ROD), was kindly supplied by Dr. Mark Mulligan (UAB).

Cell fusion assays. Fusion assays with HIV were carried out using either CD4 + HeLa cell monolayers or suspension cultures of human T lymphocytic cell lines. CD4+ HeLa cells were grown as monolayers in sterile 96-well tissue culture plates. Confluent monolayers were infected with rVV at a multiplicity of 0.05 plaque forming unit (pfu) per cell. The virus was allowed to adsorb for $1 \mathrm{~h}$ at $37^{\circ} \mathrm{C}$. The inoculum was removed and replaced with DMEM containing various concentrations of the peptides, apo A-I or HDL. The cells were incubated for $17 \mathrm{~h}$ at $37^{\circ} \mathrm{C}$. The monolayers were fixed with ethanol-acetic acid (95:5), stained with Wright-Giemsa stain, and examined microscopically for cell fusion. The area involved in fusion was determined using a Bioquant digitizer (Nashville, TN). In a second set of experiments,

1. Abbreviations used in this paper: HSV, herpes simplex virus; moi, multiplicity of infection; MTT, 3' (4,5,-dimethyl thiazole-2YL)-2,5-diphenyl tetrazolium bromide; pfu, plaque-forming unit; rVV, recombinant VV; VV, vaccinia virus.
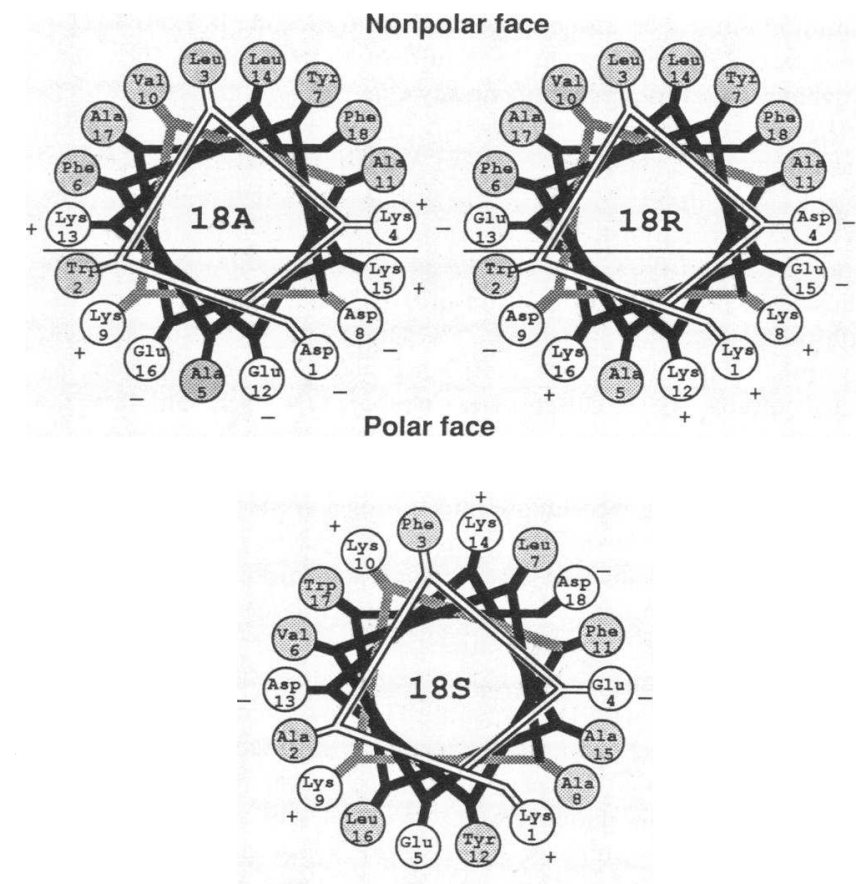

\begin{tabular}{llr} 
Peptide & \multicolumn{1}{c}{ Sequence } & $\begin{array}{c}\text { Hydrophob } \\
\text { moment/re }\end{array}$ \\
& & \\
$18 \mathrm{~A}$ & DWLKAFYDKVAEKLKEAF & 0.568 \\
$18 \mathrm{R}$ & KWLDAFYKDVAKELEKAF & 0.517 \\
$18 \mathrm{~S}$ & KAFEEVLAKKFYDKALWD & 0.054 \\
$37 \mathrm{aA}$ & $18 \mathrm{~A}-\mathrm{A}-18 \mathrm{~A}$ & 0.371 \\
$37 \mathrm{pA}$ & $18 \mathrm{~A}-\mathrm{P}-18 \mathrm{~A}$ & 0.376
\end{tabular}

Figure 1. Structure of amphipathic peptide analogue of apo A-I. Peptides $18 \mathrm{~A}, 18 \mathrm{R}$, and $18 \mathrm{~S}$ are depicted as helical wheels with a view along the axis of the $\alpha$-helix beginning at the amino terminus. Peptides $37 \mathrm{aA}$ and $37 \mathrm{pA}$ are dimers of $18 \mathrm{~A}$ covalently linked by either alanine or proline

uninfected Sup T1 cells were co-cultivated with H9 cells persistently

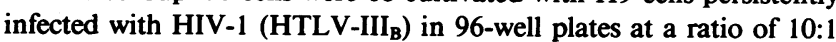
and incubated in the presence of various concentrations of peptides dissolved in RPMI medium. After $24 \mathrm{~h}$ of infection, the numbers of multinucleate giant cells were determined by microscopy.

Envelope protein synthesis and processing. Monolayers of CD4+ HeLa cells were grown to confluency in 24-well cluster plates in DMEM supplemented with 5\% NCS. Cells were infected at a multiplicity of infection (moi) of 1 with either VVenv 1 or wild-type vaccinia virus (IHD-J strain) and after a 1-h adsorption period, the supernatant was removed and replaced with $400 \mu$ l of each peptide dissolved in DMEM. At $8 \mathrm{~h}$ postinfection the cells were metabolically labeled with $\left[{ }^{35} \mathrm{~S}\right]$ methionine for $2 \mathrm{~h}$ and lysed in $0.5 \mathrm{ml}$ lysis buffer $(50 \mathrm{mM}$ Tris$\mathrm{HCl}$ pH 7.5, $0.15 \mathrm{M} \mathrm{NaCl}, 1 \%$ Triton $\mathrm{X}-100,1 \%$ sodium deoxycholate, $0.1 \%$ SDS, and $20 \mathrm{mM}$ EDTA). The lysates were immunoprecipitated using HIV immune globulins (obtained through the AIDS Research and Reference Reagent Program, AIDS Program, National Institute of Allergies and Infectious Diseases, National Institutes of Health, ERC Bioservices Corporation, MD) and protein-A Sepharose according to previously described procedures (37).

Surface expression of envelope proteins. Monolayers of CD4+ HeLa cells were grown on 12-mm glass coverslips in 24-well cluster plates in DMEM supplemented with 5\% NCS. Cells were infected at an moi of 0.1 , and treated with peptide solutions as described above. At 10 $h$ postinfection, intact unfixed monolayers were examined by indirect 
immunofluorescence assay using HIV immunoglobulin and FITCconjugated goat anti-human Ig (Southern Biotechnology, Inc., Birmingham, AL) as described previously (37).

Effect of amphipathic peptides on HIV-1 infection of MT-2 cells. The amphipathic peptides $37 \mathrm{pA}$ and $37 \mathrm{aA}$ were used at a concentration of $25 \mu \mathrm{M}$ or $50 \mu \mathrm{M}$. MT-2 cells were pretreated with the peptides for a period of $60 \mathrm{~min}$ at $37^{\circ} \mathrm{C}$ and infected with HIV-1 (HTLV-III ${ }_{\mathrm{B}}$ ) at a multiplicity of 0.03 . In a second set of experiments, an inoculum adjusted to provide a multiplicity of $0.03 \mathrm{pfu} / \mathrm{cell}$ was preincubated with the peptides for $30 \mathrm{~min}$ at $37^{\circ} \mathrm{C}$ and used to infect MT-2 cells. Controls included untreated, uninfected cultures, and untreated, infected cultures. All the cultures were incubated for a period of $48 \mathrm{~h}$ and the cells from replicate cultures were pooled, washed three times with PBS, and solubilized in guanidine isothiocyanate buffer. 10- $\mu$ l aliquots were blotted onto nitrocellulose filters using a dot-blot apparatus, and hybridized to a ${ }^{32} \mathrm{P}$-labeled HIV-1 pol gene-specific probe (Genetrack Systems, Framingham, MA) according to standard procedures (38).

Effect of amphipathic peptides on the viability of HIV-infected $M T-2$ cells. Actively growing cultures of MT-2 cells were pelleted and resuspended in growth medium at a density of $2 \times 10^{5}$ cells $/ \mathrm{ml}$. The cells were infected with HIV-1 (strain HTLV-III ${ }_{B}$ ) at a multiplicity of 0.03 or 0.003 . After a $2 \mathrm{~h}$ incubation at $37^{\circ} \mathrm{C}$, unadsorbed virus was removed by washing. The cells were resuspended at a density of $2 \times 10^{5}$ cells $/ \mathrm{ml}$ and $100-\mu \mathrm{l}$ aliquots were dispensed into 96-well microtiter plates. An equal volume of RPMI medium containing the amphipathic peptides $37 \mathrm{pA}$ or $37 \mathrm{aA}$ was added to duplicate sets of cultures. Control cultures included uninfected cultures with or without amphipathic peptides $37 \mathrm{aA}$ and $37 \mathrm{pA}$, and infected cultures without any amphipathic peptides. All the cultures were maintained at $37^{\circ} \mathrm{C}$ in a $\mathrm{CO}_{2}$ incubator. After a $3 \mathrm{~d}$ culture, the test compounds were replenished by addition of $10-\mu \mathrm{l}$ aliquots of a $20 \times$ concentrated solution of appropriate peptides. The cultures were incubated for a further $3 \mathrm{~d}$ and the percentage of viable cells was determined by adding $3^{\prime}(4,5$,-dimethyl thiazole-2-YL)-2,5-di-phenyl tetrazolium bromide (MTT) to the test plates. MTT is taken up by viable cells and converted into a colored formazan derivative. The formazan derivative was solubilized by the addition of $10 \%$ SDS in $0.01 \mathrm{~N} \mathrm{HCl}$, and the color intensity was measured by determining the optical density using an ELISA plate reader. The optical density value is a function of the amount of formazan produced, which is proportional to the number of viable cells.

\section{Results}

Peptide $18 \mathrm{~A}$ is a model amphipathic $\alpha$-helix that has been shown to mimic apo A-I in many of its interactions with phos- pholipid. Reversal of the location of the positively and negatively charged residues, so that the basic amino acid residues are no longer at the polar-nonpolar interface, produced a peptide, 18R, with greatly reduced lipid affinity. Peptides $37 \mathrm{aA}$ and $37 \mathrm{pA}$ are dimers of $18 \mathrm{~A}$ linked by either an alanine or proline residue, respectively, and have also been shown to have high lipid affinity $(19,23)$. In contrast, $18 \mathrm{~S}$, which failed to form an amphipathic helix did not show any lipid affinity (data not shown).

To investigate the inhibitory activities of peptides on HIVinduced cell fusion, we used CD4+ HeLa cells infected with the VVenv1 recombinant virus. Cells were infected with VVenv1 at a multiplicity of 0.05 , and allowed to adsorb for 2 $h$. The virus inoculum was removed and the cells were maintained for $24 \mathrm{~h}$ in DMEM with or without peptides, and analyzed for syncytium formation. The results were quantified by measuring the area of the cell monolayer involved in syncytium formation in peptide-treated samples and untreated controls and expressed as a function of concentration (Table I, Fig. 2). The peptides $18 \mathrm{~A}, 18 \mathrm{R}, 37 \mathrm{aA}$, and $37 \mathrm{pA}$ were found to inhibit virus-induced cell fusion. The inhibitory effects of all the peptides were found to be dose dependent, with nearly $100 \%$ inhibition occurring at a concentration of $100 \mu \mathrm{M}$ for peptides $18 \mathrm{~A}, 37 \mathrm{aA}$, and $37 \mathrm{pA}$. In contrast, very little inhibition was observed with peptide $18 \mathrm{R}$ at similar concentrations. The peptide $18 \mathrm{~S}$, which does not form an amphipathic helix, did not show any inhibitory activity. These results demonstrate that synthetic amphipathic peptide analogues of apo A-I inhibit HIV-induced syncytium formation at relatively low concentrations. The four amphipathic peptides were also effective in inhibiting cell fusion induced by rVV-HIV-2(ROD), which is distinct from HIV-1 in its amino acid sequence, demonstrating that the inhibitory effects of the peptides are not confined to specific strains of HIV-1.

In order to determine whether these peptides were inhibiting envelope protein synthesis or processing, VVenv1-infected cells were radiolabeled in the presence or absence of the peptides, and viral proteins analyzed by immunoprecipitation and SDS-PAGE (Fig. $3 a$ ). The level of envelope protein synthesis and processing was found to be indistinguishable in peptidetreated and untreated cells. In addition, we analyzed the ex-

Table I. Effect of Amphipathic Peptides on Cell Fusion in CD4+ HeLa Cells Infected with Recombinant Vaccinia Vectors Expressing HIV-envelope Proteins

\begin{tabular}{|c|c|c|c|c|c|c|}
\hline \multirow[b]{2}{*}{ Virus } & \multirow[b]{2}{*}{ Peptide } & \multicolumn{4}{|c|}{ \% Fusion inhibition $( \pm \mathrm{SD})^{*}$ at peptide concentration of } & \multirow[b]{2}{*}{$\mathrm{ID}_{\mathbf{5 0}}$} \\
\hline & & $12.5 \mu \mathrm{M}$ & $25.0 \mu \mathrm{M}$ & $50.0 \mu \mathrm{M}$ & $100.0 \mu \mathrm{M}$ & \\
\hline & & & & & & $\mu M$ \\
\hline \multirow[t]{5}{*}{ VVenv1 } & $18 \mathrm{~A}$ & $29.7( \pm 2.3)$ & $42.0( \pm 4.0)$ & $71.2( \pm 2.9)$ & $93.9( \pm 2.3)$ & 30 \\
\hline & $18 \mathrm{R}$ & $7.7( \pm 1.1)$ & $2.7( \pm 3.1)$ & $28.8( \pm 1.8)$ & $40.6( \pm 4.2)$ & $>100$ \\
\hline & $37 \mathrm{aA}$ & $36.5( \pm 5.8)$ & $36.5( \pm 10.7)$ & $63.2( \pm 5.5)$ & $96.2( \pm 2.2)$ & 30 \\
\hline & $37 \mathrm{pA}$ & $46.6( \pm 4.9)$ & $52.1( \pm 4.4)$ & $76.2( \pm 6.2)$ & $83.2( \pm 3.1)$ & 20 \\
\hline & $18 S$ & 0 & $2.7( \pm 0.8)$ & $3.5( \pm 0.5)$ & $5.1( \pm 1.1)$ & $>100$ \\
\hline \multirow[t]{3}{*}{ VV-ROD } & $18 \mathrm{~A}$ & $40.1( \pm 6.9)$ & $52.7( \pm 5.3)$ & $83.6( \pm 3.0)$ & $98.9( \pm 3.0)$ & 20 \\
\hline & $18 R$ & $8.0( \pm 1.0)$ & $16.5( \pm 3.6)$ & $33.9( \pm 3.4)$ & $44.4( \pm 2.7)$ & $>100$ \\
\hline & $18 \mathrm{~S}$ & 0 & $1.9( \pm 0.2)$ & $5.6( \pm 1.3)$ & $6.0( \pm 2.9)$ & $>100$ \\
\hline
\end{tabular}

The area of monolayer involved in cell fusion was determined using a digitizer as described in Methods, and the results were expressed as percentage of area involved in fusion in cultures without any peptides. The average area involved in fusion was $25 \%$ of the monolayer in control cultures. * Each figure represents a mean of three separate experiments. 

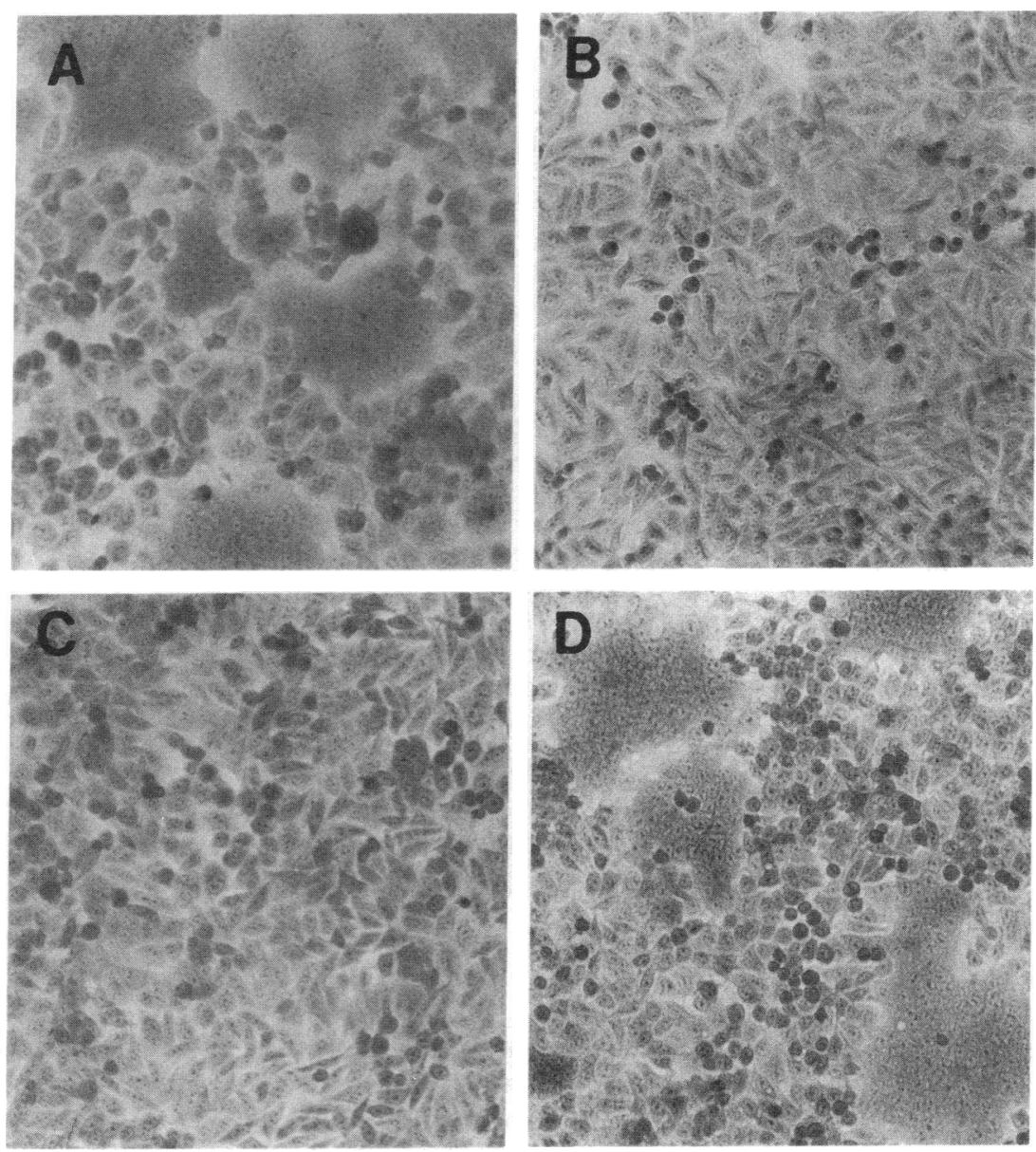

b

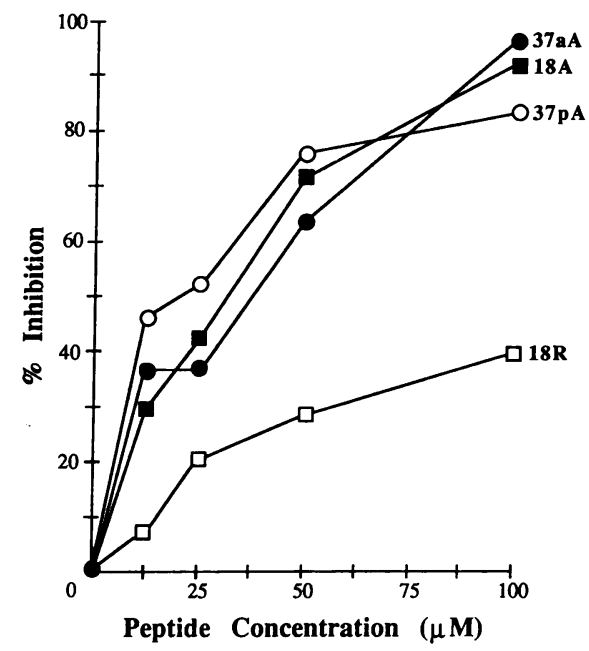

Figure 2. Inhibition of HIV-induced syncytium formation by amphipathic helical peptides. CD4+ HeLa cells were infected with recombinant vaccinia virus (VVenv1) $(A, C$, and $D$ ) or wild type vaccinia virus (IHD-J strain) $(B)$. Cells in $C$ were treated with $100 \mu \mathrm{M}$ of peptide $18 \mathrm{~A}$, and in $D$, with $100 \mu \mathrm{M}$ of peptide $18 \mathrm{R}$.

pression of the envelope protein on the cell surface by immunofluorescence, and no differences in surface expression were detected in peptide-treated cells and untreated controls (Fig. 3 b). These results suggest that the inhibitory effects of the peptides are exerted directly upon the fusion process.

To determine whether the amphipathic peptides were also capable of inhibiting syncytium formation in HIV-infected T cells, the helper $\mathrm{T}$ cell line Sup $\mathrm{T} 1$ was co-cultivated with $\mathrm{H} 9$ cells persistently infected with $\mathrm{HIV}-\mathrm{III}_{B}$ in the presence of various concentrations of each peptide, and scored for syncytium formation $18 \mathrm{~h}$ later. As found with the VVenv1 recombinant, marked inhibition of syncytium formation was observed with peptides $18 \mathrm{~A}, 37 \mathrm{aA}$, and $37 \mathrm{pA}$, while inhibition by $18 \mathrm{R}$ was negligible. Table II summarizes the results from both recombinant vaccinia-virus-infected cells and HIV-1-infected cells and compares the $\mathrm{ID}_{50}$ (concentration required for $50 \%$ syncytium inhibition) for all of the peptides tested.

Because the amphipathic peptide analogues of apo A-I were found to be effective inhibitors of cell fusion, we also analyzed the inhibitory activity of the parent apo A-I molecule. CD4+ HeLa cells were infected with the VVenv1 recombinant at an moi of 0.05 and incubated with various concen- trations of apo A-I. 54\% inhibition was observed at a concentration of $4 \mu \mathrm{M}$, reaching a maximum of $67 \%$ inhibition at 8 $\mu \mathrm{M}$. However, when the cells were exposed to higher concentrations of apo A-I, they were observed to round up and become detached from the culture plates.

The process involved in cell-to-cell fusion is thought to be analogous to the processes involved in fusion of viral membrane to the cell membrane during virus penetration (39). We therefore investigated the effects of amphipathic peptides $37 \mathrm{aA}$ and $37 \mathrm{pA}$ on HIV-1 (HTLV-III ${ }_{B}$ ) infection in MT-2 cells (see Methods). The effect on virus replication was monitored by assaying for virus-specific RNA in the cells' lysates at $48 \mathrm{~h}$ postinfection by dot-blot hybridization using a HIV-1 pol gene-specific probe (Fig. 4). Cell lysates from untreated, virus-infected controls yielded a strong signal, nearly twice as intense as the 1-ng virus standard. No nonspecific hybridization was observed in uninfected cells. A significant decrease in virus-specific RNA levels was observed in cells infected with virus pretreated with either $37 \mathrm{aA}$ or $37 \mathrm{pA}$. The inhibition was found to be dose dependent, and was observed at $50 \mu \mathrm{M}$ (but not $25 \mu \mathrm{M})$ concentrations of the peptides. In contrast, no significant reduction in HIV-1 replication was observed in 
MT-2 cells pretreated with either of the peptides (Fig. 4). Together, these results indicate that the peptides may interact with some component of HIV virions and lead to an inactivation of virus infectivity.

To determine the effects of peptide treatment on HIV-infected cell cultures, we monitored the viability of HIV-1-infected MT-2 cultures ( $\mathrm{moi}=0.03$ or 0.003 ), maintained in the presence or absence of the amphipathic peptides $37 \mathrm{pA}$ or $37 \mathrm{aA}$ by a colorimetric assay based on uptake of chromogenic substrate MTT. The results are summarized in Table III. Over a 6-d period, the number of viable cells in cultures infected with HIV-1 at a multiplicity of 0.03 was $30 \%$ of the total viable cells in uninfected controls. No detectable increase in the number of viable cells was observed with the peptide $37 \mathrm{aA}$ at concentration of $25 \mu \mathrm{M}$. However, the percentage of viable cells increased to $36 \%$ in cultures maintained at $50 \mu \mathrm{M} 37 \mathrm{aA}$ or 25 $\mu \mathrm{M} 37 \mathrm{pA}$, and to $46 \%$ in cultures maintained at $50 \mu \mathrm{M} 37 \mathrm{pA}$, thus demonstrating an increase in the number of viable cells in peptide-treated cultures. This increase was more readily observed in cultures infected at a lower multiplicity. The number of viable cells in untreated, HIV-1-infected $(0.003 \mathrm{pfu} / \mathrm{cell})$ cultures was $40 \%$ of the total viable cells in uninfected controls. The viable cell numbers were $61 \%$ and $68 \%$, respectively, in cultures treated with $50 \mu \mathrm{M} 37 \mathrm{aA}$ or $37 \mathrm{aA}$, as compared to $40 \%$ in untreated cultures. Cell killing in HIV-infected cultures has been attributed to syncytium formation, as well as singlecell killing of virus-infected cells. Possibilities which may account for the observed increase in the number of viable cells in peptide-treated cultures include: $(a)$ an inhibition in syncytium formation which is thought to be responsible for killing uninfected CD4+ cells; $(b)$ a reduction in the infectivity of progeny virus, thus leading to a reduction in the number of secondarily infected cells; or $(c)$ a direct effect on the viability of HIV-infected cells. Further studies are required to identify which of these factors may account for increased viability in peptide-treated, HIV-infected cultures.

In order to determine whether the apo A-I and its amphipathic peptide analogues inhibit other fusogenic, enveloped viruses, we investigated their effects on herpes simplex virus (HSV-1). Apo A-I was found to inhibit HSV-1, MP-induced cell fusion at physiological $(\sim 1 \mu \mathrm{M})$ concentrations. The peptides $18 \mathrm{~A}, 37 \mathrm{aA}$, and $37 \mathrm{pA}$ also inhibited $\mathrm{HSV}$-induced cell fusion and the $\mathrm{ID}_{100}$ values were 2,4 , and $2 \mu \mathrm{M}$, respectively. In contrast, the peptide $18 \mathrm{R}$, in which the distribution of charged residues was reversed, inhibited virus-induced cell fusion only at a much higher $(\sim 125 \mu \mathrm{M})$ concentration. Consistent with their ability to inhibit virus-induced cell fusion, the peptides inhibited the spread of HSV infection as demonstrated by a 10 -fold reduction in the yields of both highly fusogenic strain MP, and the wild-type McIntyre strain of HSV, when virus-infected cells were maintained in the presence of amphipathic peptides. The amphipathic peptides also inhibited penetration of HSV into cells. A nearly complete inhibition of virus penetration was observed when the virus, or both virus and cells, was pretreated with the peptide, suggesting that the peptides may have a direct effect on the virus. A detailed description of these results are presented elsewhere (40).

In order to further study the specificity of the inhibitory effects of amphipathic peptides, we investigated their effects on the replication of nonenveloped poliovirus. Cells infected with poliovirus (10 $\left.\mathrm{TCID}_{50}\right)$ were maintained in the presence or

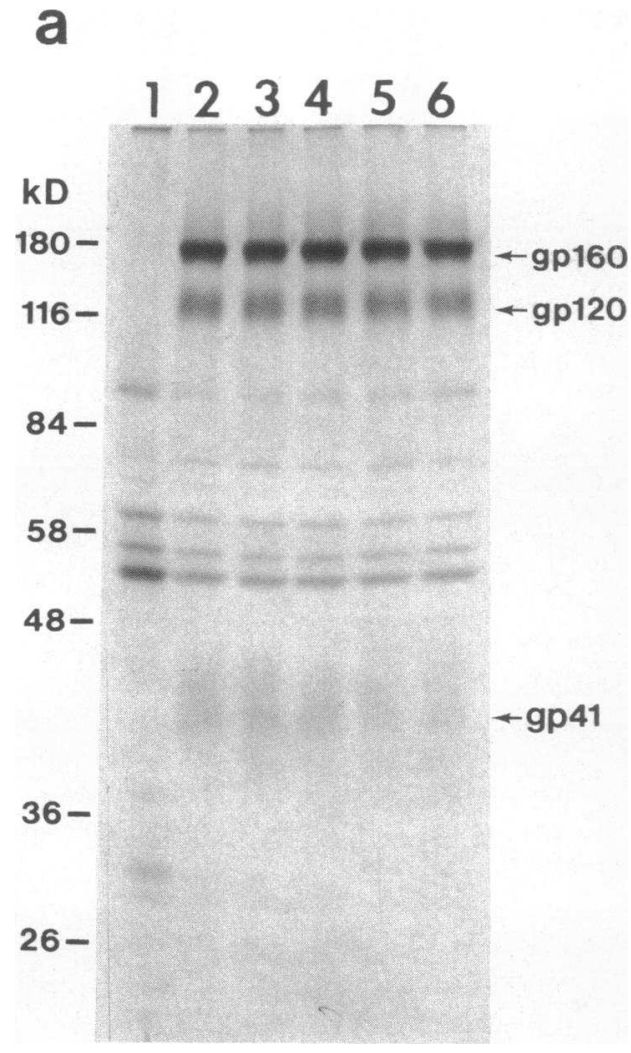

Figure 3

absence of serial twofold dilutions of the peptides $18 \mathrm{~A}$ and $18 \mathrm{R}$, and observed for poliovirus-induced cytopathology $24 \mathrm{~h}$ after infection. Cells pretreated with the peptides for $24 \mathrm{~h}$ were also infected with $10 \mathrm{TCID}_{50}$ dose of poliovirus to determine whether peptide treatment inhibits the binding or entry of the virus. In another experiment, the cells were pretreated with the peptide, and peptide treatment was maintained both during adsorption and throughout the infection period. No inhibition of poliovirus infection was observed in any of these experiments at peptide concentrations as high as $500 \mu \mathrm{M}$. These results indicate that the inhibitory effect of amphipathic peptides is specific for enveloped viruses.

The amphipathic peptides may be regarded as peptide detergents. In an attempt to determine whether the fusion-inhibitory properties of the peptides are related to their detergentlike properties, we also investigated the fusion-inhibitory properties of a known detergent, sodium desoxycholate (DOC). Uninfected or VVenvl-infected HeLa T4 cells were maintained in the presence of varying concentrations of DOC and examined for cell viability and fusion. DOC at concentrations above $125 \mu \mathrm{M}$ was toxic to the cells. However, there was $\sim 50 \%$ inhibition in VVenv1-induced cell fusion at a concentration of $62.5 \mu \mathrm{M}$ DOC. Thus, unlike amphipathic peptides, the inhibitory concentration of the detergent was very close to its toxicity limit.

\section{Discussion}

We have demonstrated that apo A-I and its synthetic, amphipathic $\alpha$-helical peptide analogues are effective inhibitors of HIV-induced syncytium formation. A feature of the most ef- 

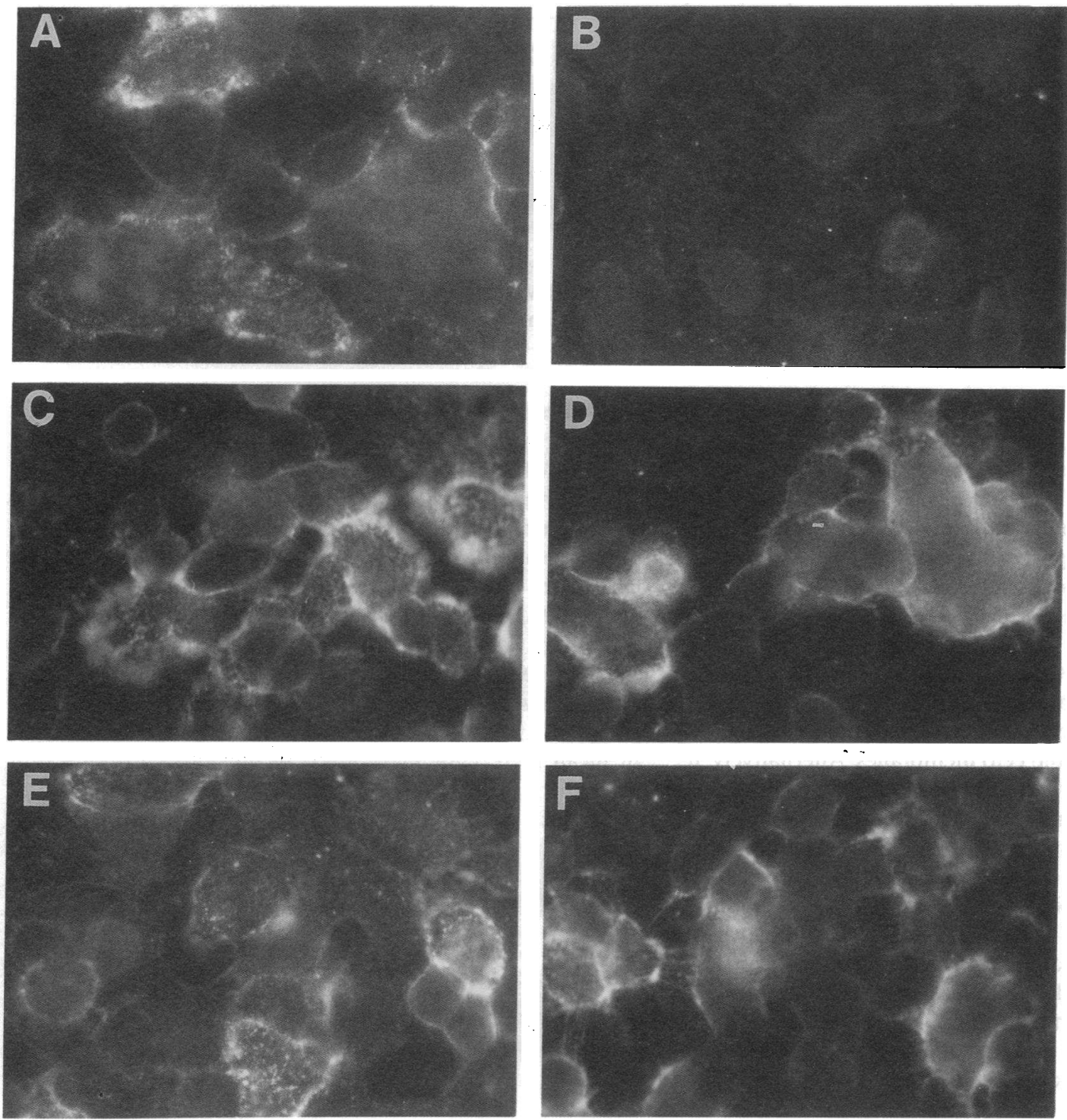

Figure 3. Envelope protein synthesis and transport in the presence of in hibitory peptides. (a) Immunoprecipitation of envelope proteins. Lane 1 , wild-type vaccinia-infected cells; lanes 2-7, VVenv1-infected cells; lane 2 , no peptide; lane 3 $100 \mu \mathrm{M}$ 18A; lane 4, 100 $\mu \mathrm{M}$ 18R; lane 5, $100 \mu \mathrm{M}$ 37aA; lane 6, $100 \mu \mathrm{M}$ 37pA; and lane 7, $8 \mu \mathrm{M}$ apo A-I. Peptide treatment had no effect on the level of protein synthesis or processing of the gp160 precursor as compared to the untreated control. (b) Surface expression of envelope proteins. $A, C-F$, VVenv1infected cells; $B$, wildtype vaccinia control. $A$, no peptide; $C, 100 \mu \mathrm{M}$ 18A; $D, 100 \mu \mathrm{M} 18 \mathrm{R} ; E$, $100 \mu \mathrm{M} 37 \mathrm{aA}$; and $F, 100$ $\mu$ M 37pA. Relative levels of fluorescence were the same in peptide-treated samples as in the untreated control, indicating that the peptides were not blocking transport of the envelope protein to the cell surface. fective inhibitors seems to be the positioning of basic amino acid residues at the polar-nonpolar interface of the amphipathic helix. When the positions of basic and acidic residues were exchanged on the polar surface (in the case of peptide $18 R$ ), inhibitory activity was greatly reduced. The reason for this is not immediately clear; however, the hydrophobic portion of the lysine and arginine side chains clustering at the polar-nonpolar interface could allow the amphipathic helix to bury itself deeper in the lipid bilayer or increase its affinity for hydrophobic protein domains, such as the fusion domain at the $\mathrm{NH}_{2}$ terminus of gp41.

We have previously shown that the three peptides $18 \mathrm{~A}$, $18 \mathrm{R}$, and $37 \mathrm{pA}$ have a relative lipid affinity of $37 \mathrm{pA}>18 \mathrm{~A}$ $\rightarrow 18 \mathrm{R}(19)$. While $18 \mathrm{R}$ with the lowest lipid affinity was least effective in inhibiting virus-induced cell fusion, $18 \mathrm{~A}$ was just as active as $37 \mathrm{pA}$ in inhibiting virus-induced cell fusion. Thus there appears to be no absolute correlation between lipid affinity of the amphipathic peptides and their ability to inhibit virus-induced cell fusion, suggesting that the inhibition of virus-induced cell fusion mediated by the peptides may not be mediated merely by the lipid binding of these peptides. Consistent with their ability to inhibit cell fusion, the amphipathic

Table II. Inhibition of HIV-1-induced Cell Fusion by Amphipathic Peptides

\begin{tabular}{crr}
\hline & \multicolumn{2}{c}{ ID $_{s 0}(\mu M)$} \\
\cline { 2 - 3 } Peptide & VVenv1* $^{*}$ & HIV-1* \\
\hline $18 \mathrm{~A}$ & 30 & 40 \\
$18 \mathrm{R}$ & $>100$ & $>250$ \\
$37 \mathrm{aA}$ & 30 & 15 \\
$37 \mathrm{pA}$ & 20 & 40 \\
\end{tabular}

* ID so values were extrapolated from plots in Fig. $2 b$.

${ }^{\ddagger} \mathrm{ID}_{50}$ values were obtained using a co-cultivation assay to generate the data. 

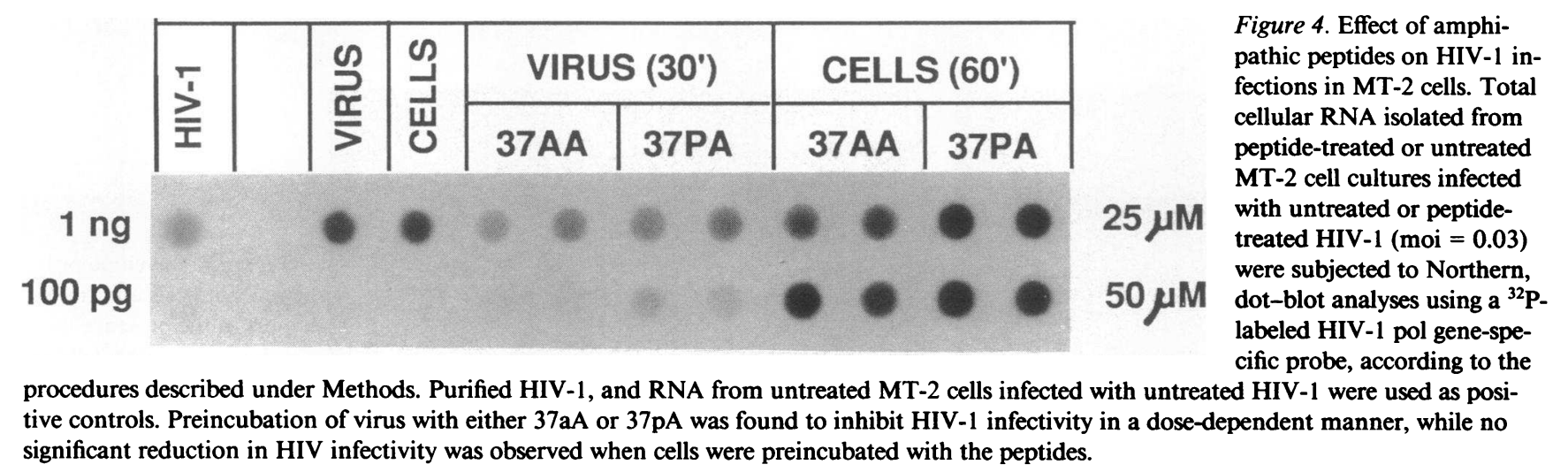

procedures described under Methods. Purified HIV-1, and RNA from untreated MT-2 cells infected with untreated HIV-1 were used as positive controls. Preincubation of virus with either $37 \mathrm{aA}$ or $37 \mathrm{pA}$ was found to inhibit HIV-1 infectivity in a dose-dependent manner, while no significant reduction in HIV infectivity was observed when cells were preincubated with the peptides.

peptides also inhibited HIV infectivity, when the virus was pretreated with the peptides.

The exact mechanism by which apo A-I and its peptide analogues exert their inhibitory effects is not known; however, several possibilities are outlined in Fig. 5. One possibility is that the amphipathic peptides may perturb the lipid bilayer organization of either the viral membrane, or the cell membrane, or both, and alter its fusogenic properties. Perhaps inhibition is related in some way to the presence of putative amphipathic helixes in gp120 and gp41. If amphipathic domains are involved in gp120-gp41 subunit interactions, the apo A-I amphipathic peptides may disrupt this association, leading to a loss of gp 120 from viral (and cell) membranes. Alternatively, if the carboxy-terminal gp41 amphipathic domains play some role in mediating virus entry and cell fusion, the apo A-I amphipathic peptides may interact with these domains and disrupt their normal function. Also, the nonpolar surface of the amphipathic helix could be associating with the fusogenic domain of gp41, thereby preventing it from interacting with a target membrane. Pretreatment of CD4+ cells with the peptides failed to inhibit HIV infection. It is therefore unlikely that these compounds bind to a putative "fusion receptor" and block its interaction with the fusogenic domain of the envelope protein, or with the binding of gp120 to the CD4 receptor.

Table III. Viability of HIV-I (HTLV-III $\left.{ }_{B}\right)$ Infected MT-2 Cells Maintained in Presence of Amphipathic Peptides

\begin{tabular}{lcc}
\hline & \multicolumn{2}{c}{$\%$ Viability in cultures infected at } \\
\cline { 2 - 3 } \multicolumn{1}{c}{ Treatment } & 0.03 moi & 0.003 moi \\
\hline Uninfected & $100^{*}$ & 100 \\
Infected, no peptide & 30 & 40 \\
Infected, 37aA $(25 \mu \mathrm{M})$ & 30 & 40 \\
Infected, 37aA $(50 \mu \mathrm{M})$ & 36 & 61 \\
Infected, 37pA $(25 \mu \mathrm{M})$ & 36 & 48 \\
Infected, 37pA $(50 \mu \mathrm{M})$ & 46 & 68
\end{tabular}

The optical density of the formazan derivative was used as a measure of total number of viable cells in the culture. The results are expressed as percentage of viable cells, as compared to values obtained with uninfected controls.

* Figures indicate percent viability as determined by a colorimetric assay based on uptake and conversion of a chromogenic substrate MTT by viable cells.
Experiments are currently underway to determine the site of action for apo A-I and its analogues.

Apo A-I is the major protein component of HDL. High plasma levels of HDL have been found to be a common and perhaps hereditary factor for long-lived individuals; not all of this longevity can be accounted for by protection from coronary artery disease (41). While hypertriglyceridemia has been reported to be a common finding in AIDS (42), to our knowledge there have been no studies that address whether low plasma levels of HDL are associated with HIV infection. In a retrospective study of 35 male HIV seropositive subjects compared with healthy controls, we found a significant reduction in mean HDL cholesterol levels in previously frozen serum

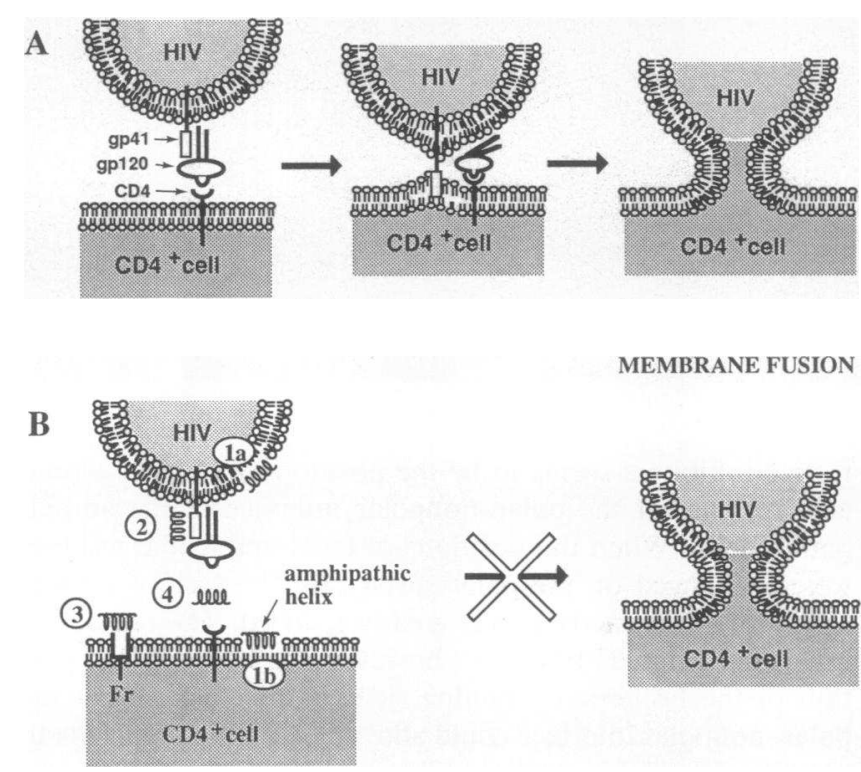

Figure 5. Model of possible sites of inhibition of HIV-induced membrane fusion by the amphipathic helix. $(A)$ Membrane fusion in the absence of peptide treatment. The first step requires an interaction between gp 120 and the CD4 receptor, to bring the two membranes into close proximity. Then, gp41 probably perturbs the membrane bilayers (by an unknown mechanism) resulting in fusion of the two membranes. $(B)$ The amphipathic helix could be acting at one or a combination of the above sites: $1 \mathrm{a}$ and/or $1 \mathrm{~b}$, perturbation of the lipid bilayer; 2 , interaction with the fusogenic domain in gp $41 ; 3$, interaction with a specific fusion receptor (Fr); or 4 , interfering with gp120-CD4 binding. 
samples from patients with frank AIDS, or AIDS-related complex (ARC), as well as in asymptomatic individuals. In order to rule out the possibility of artifactual HDL lowering secondary to freeze-thaw damage, three separate control studies were performed. In these studies, control sera were subjected to identical storage conditions (freezing and thawing) as the sera from HIV positive patients. Unfortunately, the results of the three studies have given conflicting results, thus leaving open the question of an association of low HDL levels with HIV infectivity. Additionally, the question of low HDL being the consequence of HIV infectivity, as opposed to being a preexisting risk factor, cannot be resolved without prospective study of plasma HDL levels in individuals at high risk for development of infection. Nevertheless, no matter what the role of HDL as a possible risk factor for HIV infection, it is important to consider synthetic amphipathic peptides themselves as potential therapeutic agents.

\section{Acknowledgments}

We thank Kiran Gupta, Cris McGee, and Cynthia Tanner for excellent technical assistance, and Eugene Arms for photography.

This study was supported by grants HL-34343, CA-40440, AI-25784 from the National Institutes of Health and the Center for AIDS Research, Birmingham. Dr. Owens was supported in part by Institutional Research Service Award AI-07150 from the National Institutes of Health.

\section{References}

1. Robey, W. G., B. Safai, S. Oroszlan, L. O. Arthur, M. A. Gonda, R. C. Gallo, and P. J. Fischinger. 1985. Characterization of envelope and core structural gene products of HTLV-III with sera from AIDS patients. Science (Wash. DC). 228:1402-1405.

2. Chakrabarti, S., M. Robert-Guroff, F. Wong-Staal, R. C. Gallo, and B. Moss. 1986. Expression of the HTLV-III envelope gene by a recombinant vaccinia virus. Nature (Lond.). 320:535-537.

3. Veronese, F. D., A. L. DeVico, T. D. Copeland, S. Oroszlan, R. C. Gallo, and M. G. Sarngadharan. 1985. Characterization of gp41 as the transmembrane protein coded by the HTLV-III/LAV envelope gene. Science (Wash. DC). 229:1402-1405.

4. Hu, S-L., S. G. Kosowski, and J. M. Dalrymple. 1986. Expression of AIDS virus envelope gene in recombinant vaccinia viruses. Nature (Lond.). 320:537-540.

5. McCune, J. M., L. B. Rabin, M. B. Feinberg, M. Lieberman, J. C. Kosek, G. R. Reyes, and I. L. Weissman. 1988. Endoproteolytic cleavage of gp 160 is required for the activation of human immunodeficiency virus. Cell. 53:55-67.

6. Maddon, P. J., A. G. Dalgleish, J. S. McDougal, P. R. Clapham, R. A. Weiss, and R. Axel. 1986. The T4 gene encodes the AIDS virus receptor and is expressed in the immune system and the brain. Cell. 47:333-348.

7. Stein, B. S., S. D. Gowda, J. D. Lifson, R. C. Penhallow, K. G. Bensch, and E. G. Engleman. 1987. pH-Independent HIV entry into CD4-positive $T$ cells via virus envelope fusion to the plasma membrane. Cell. 49:659-668.

8. Richardson, C. D., and P. W. Choppin. 1983. Oligopeptides that specifically inhibit membrane fusion by paramyxovirus: studies on the site of action. Virology. 131:518-532.

9. Richardson, C. D., A. Scheid, and P. W. Choppin. 1980. Specific inhibition of paramyxovirus and myxovirus replication by oligopeptides with amino acids similar to those at the N-termini of the F1 or HA2 viral polypeptides. Virology. 105:204-222.

10. Norrby, E. 1971. The effect of a carbobenzoxy tripeptide on the biological activities of measles virus. Virology. 44:599-608.

11. Nicolaides, E., H. DeWald, R. Westland, M. Lipnick, and J.
Posler. 1968. Potential antiviral agents. Carbobenzoxy di- and tripeptides active against measles and herpes virus. J. Med. Chem. 11:74-79.

12. Miller, F. A., G. J. Dixon, G. Arnett, J. R. Dice, W. A. Rightsel, F. M. Schabel, Jr., and I. W. McLean, Jr. 1968. Antiviral activity of carbobenzoxy di- and tripeptides on measles virus. Appl. Microbiol. 16:1489-1496.

13. Dice, J. R., W. A. Rightsel, F. M. Schabel, and I. W. McLean. 1965. Experiences in developing potential antiviral compounds. Ann. N.Y. Acad. Sci. 130:24-30.

14. Epand, R. M. 1986. Virus replication inhibitory peptides inhibits the conversion of phospholipid bilayers to the hexagonal phase. Biosci. Rep. 6:647-653.

15. Epand, R. M., E. F. Epand, and R. C. Mckenzie. 1987. Effect of viral chemotherapeutic agents on membrane properties: studies of cyclosporin A, carbobenzoxy-D-Phe-L-Gly and amantadine. J. Biol. Chem. 262:1526-1529.

16. Perutz, M. F., J. C. Kendrew, and H. C. Watson. 1965. Structure and function of hemoglobin II. Some relations between polypeptide chain configuration and amino acid sequence. J. Mol. Biol. 13:669-678.

17. Schiffer, M., and A. B. Edmundson. 1967. Use of helical wheels to represent the structures of proteins and to identify segments with helical potential. Biophys. J. 7:121-135.

18. Segrest, J. P., R. L. Jackson, J. D. Morrisett, and A. M. Gotto, Jr. 1974. A molecular theory of lipid-protein interactions in the plasma lipoproteins. FEBS (Fed. Eur. Biochem. Soc.) Lett. 38:247-253.

19. Anantharamaiah, G. M., J. L. Jones, C. G. Brouillette, C. F. Schmidt, B. H. Chung, A. S. Bhown, T. A. Hughes, and J. P. Segrest. 1985. Studies of synthetic peptide analogs of the Amphipathic helix. I. Structure of peptide/DMPC complexes. J. Biol. Chem. 260:1024810253.

20. Chung, B. H., G. M. Anantharamaiah, C. G. Brouillette, T. Nishida, and J. P. Segrest. 1985. Studies of synthetic peptide analogs of the amphipathic helix II. Structure-function correlation. J. Biol. Chem. 260:10256-10262.

21. Kanellis, P., A. Y. Romans, B. Johnson, H. Kercert, R. Chiovetti, Jr., T. M. Allen, and J. P. Segrest. 1980. Studies of synthetic peptide analogs of the amphipathic helix: effect of charged amino acid residue topography on lipid affinity. J. Biol. Chem. 255:1 1464-11472.

22. Epand, R. M., A. Gawish, M. Iqbal, K. B. Gupta, C. H. Chen, J. P. Segrest, and G. M. Anantharamaiah. 1987. Studies of synthetic peptide analogs of the amphipathic helix: effect of charge distribution on lipid association and lecithin:cholesterol acyl transferase activation. J. Biol. Chem. 262:9389-9396.

23. Lund-Katz, S., J. A. Ibdah, G. M. Anantharamaiah, J. P. Segrest, and M. C. Philips. 1988. NMR investigation of the interactions with phospholipid of an amphipathic a-helix-forming peptides. Circulation. 78:288.

24. Sparrow, J. T., and A. M. Gotto, Jr. 1982. Apolipoprotein/lipid interactions: studies with synthetic polypeptides. CRC Crit. Rev. Biochem. 13:87-107.

25. Venkatachalapathi, Y. V., K. B. Gupta, H. DeLoof, J. P. Segrest, and G. M. Anantharamaiah. 1990. Positively charged amino acid residues, because of their amphipathic nature, can increase lipid affinities of amphipathic helixes. In Peptides, Proceedings of Eleventh American Peptide Symposium. J. E. Rivier and G. R. Marshall, editors. ESCOM Science Publishers B.V., Leiden, Netherlands. 672-673.

26. Taylor, J. W., and E. T. Kaiser. 1986. The structural characterization of beta-endorphin and related peptide hormones and neurotransmitters. Pharmacol. Rev. 38:291-319.

27. Zasloff, M. 1987. Magainins, a class of antimicrobial peptides from Xenopus skin: isolation, characterization of two active forms, and partial cDNA sequence of a precursor. Proc. Natl. Acad. Sci. USA. 84:5449-5453.

28. Boman, H. G., I. Faye, V. P. Holsten, K. Kockum, J.-Y. Lee, and K. G. Xanthopoulos. 1985. On the primary structure of lysozyme, cecropins and attacins from Hyalophora cecropia. Dev. Comp. Immunol. 9:551-558. 
29. DeGrado, W. F., Z. R. Wasserman, and V. Chowdhry. 1982. Sequence and structural homologies among type I and type II interferons. Nature (Lond.). 300:379-381.

30. Eisenberg, D., and M. Wesson. 1990. The most highly amphiphilic alpha-helices include two amino acid segments in human immunodeficiency virus glycoprotein 41. Biopolymers. 29:171-177.

31. McPhee, D. A., S. A. Cumming, N. C. Pavuk, R. R. Doherty, D. I. Stapleton, and B. E. Kemp. 1989. Putative contact region between HIV envelope proteins gp120 and gp41: antiviral action of synthetic peptide analogs. In Vaccines (Cold Spring Harbor) 89. R. A. Lerner, H. Ginsberg, R. M. Chanock, and F. Brown, editors. Cold Spring Harbor Laboratory, Cold Spring Harbor, NY. 185-189.

32. Haffar, O. K., D. J. Dowbenko, and P. W. Berman. 1987 Topogenic analysis of HIV type 1 envelope glycoprotein, gp160, in microsomal membranes. J. Cell Biol. 107:1677-1687.

33. Dubay, J. L., J. Kong, J. Kappes, G. Shaw, B. Hahn, and E. Hunter. 1988. Mutational analysis of gp41 glycoprotein. IV International Conference on AIDS. Stockholm, Sweden. (Published by Meeting) 1517:54. (Abstr.)

34. Sodroski, J., M. Kowalski, and W. Haseltine. 1988. Determinants of HIV entry, cell-to-cell transmission, and cell killing. In Cell Biology of Virus Entry, Replication and Pathogenesis. A. Helenius, R. W. Compans, and M. B. A. Oldstone, editors. Alan R. Liss Inc., New York. 119-124.

35. Anantharamaiah, G. M., T. A. Hughes, M. Iqbal, A. Gawish,
P. J. Neame, M. F. Medley, and J. P. Segrest. 1987. Effect of oxidation on the properties of apolipoproteins A-I and A-II. J. Lipid Res. 29:309-318.

36. Harda, S., Y. Koyanagi, and N. Yamamoto. 1985. Infection of HTLVIII/LAV in HTLV-I-carrying cells MT-2 and MT-4 and application in a plaque assay. Science (Wash. DC). 229:563-566.

37. Owens, R. J., and R. W. Compans. 1989. Expression of the human immunodeficiency virus envelope glycoprotein is restricted to basolateral surfaces of polarized epithelial cells. J. Virol. 63:978-982.

38. Sambrook, J., E. F. Fritsch, and T. Maniatis. 1989. Molecular cloning: A Laboratory Manual. 2nd ed. Cold Spring Harbor Laboratory Press, Cold Spring Harbor, NY. 545 pp.

39. White, J., M. Kielian, and A. Helenius. 1983. Membrane fusion proteins of enveloped animal viruses. $Q$. Rev. Biophys. 16:151-195.

40. Srinivas, R. V., B. Birkedal, R. J. Owens, G. M. Anantharamaiah, J. P. Segrest, and R. W. Compans. 1990. Antiviral effects of apolipoprotein A-1 and its synthetic amphipathic peptide analogs. $\mathrm{V}$ rology. 176:48-57.

41. Gleuck, C. J., P. Gartside, and R. W. Fallot. 1976. Longevity syndromes: familial hypobeta and hyperalpha lipoprotenemia. J. Lab. Clin. Med. 88:941-957.

42. Grunfield, C., D. P. Kotler, R. Hemadeh, A. Tierney, J. Wang, and R. N. Pierson. 1989. Hypertriglyceridemia in the acquired immunodeficiency syndrome. Am. J. Med. 86:27-31. 